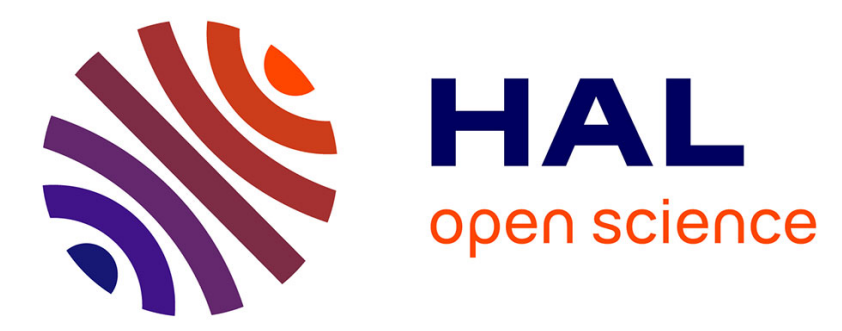

\title{
Direct Shear Behavior of a Mixture of Sand and Tire Chips Using X-ray Computed Tomography and Discrete Element Method
}

Bastien Chevalier, Yohei Tsutsumi, Jun Otani

\section{- To cite this version:}

Bastien Chevalier, Yohei Tsutsumi, Jun Otani. Direct Shear Behavior of a Mixture of Sand and Tire Chips Using X-ray Computed Tomography and Discrete Element Method. International Journal of Geosynthetics and Ground Engineering, 2019, 5 (2), pp.7. 10.1007/s40891-019-0160-3 . hal-02061524

HAL Id: hal-02061524

https://hal.uca.fr/hal-02061524

Submitted on 17 Nov 2020

HAL is a multi-disciplinary open access archive for the deposit and dissemination of scientific research documents, whether they are published or not. The documents may come from teaching and research institutions in France or abroad, or from public or private research centers.
L'archive ouverte pluridisciplinaire HAL, est destinée au dépôt et à la diffusion de documents scientifiques de niveau recherche, publiés ou non, émanant des établissements d'enseignement et de recherche français ou étrangers, des laboratoires publics ou privés. 


\title{
Direct shear behavior of a mixture of sand and tire chips using X-ray computed tomography and discrete element method
}

\author{
Bastien Chevalier ${ }^{1)}$, Yohei Tsutsumi ${ }^{2)}$, Jun Otani ${ }^{3)}$
}

Corresponding author: Jun Otani junotani@kumamoto-u.ac.jp

1) Université Clermont Auvergne, CNRS, SIGMA Clermont, Institut Pascal, F-63000 Clermont-Ferrand, France

2) Tokyo Metropolitan Government, Nishi-Shinjuku 2-8-1, Shinjuku-ku, Tokyo 1638001, Japan

3) X-earth Center, Kumamoto University, Kurokami 2-39-1, Chuo-ku, Kumamoto 8608555, Japan 


\section{Abstract}

Granular materials such as soils, powders, and other particulate materials have been widely used in geotechnical engineering. In particular, sandy soils are one of the representative ones. Recently, there has been attention on environment friendly materials such as tire chips or other waste materials. Besides, one of the key behaviors for these materials is shear behavior, including the effect of dilatancy. In this paper, direct shear behavior of sands as rigid particles and tire chips as elastic particles is discussed. Here, micro-focus type X-ray computed tomography (CT) scanner is used with direct shear tests to investigate the close behavior in granular materials. To discuss the results of CT scanning quantitatively, a digital image correlation method is used and then, the distribution of the displacements in the shear box, shear strain, and volumetric strain are measured using CT data. In addition, a series of numerical analysis using discrete element method (DEM), which is often used for granular materials, is carried out for the same cases as direct shear test to validate the CT results. Finally, based on the comparative discussion between test results with CT scanning and DEM results, the direct shear behavior of different granular materials is precisely investigated for the first time using X-ray CT. The use of tire chips mixed with sand decreases the dilatant behavior under shear stress, and the peaks in shear stress are no longer observed. In addition, tire chips 
seem to prevent shear bands to propagate in the material.

Keywords: Discrete element method, direct shear test, displacement, failure, granular materials, X-ray CT.

\section{Introduction}

Direct shear test is a classical technique to determine the shear strength of geomaterials such as friction angle and cohesion. However, it has several limitations such as imposed stress path, imposed failure plane, difficulty in controlling the pore pressure in the sample and the effect of particle size [1]. Despite these limitations, the fact that this test is very simple and quick to perform makes it viable in the field of geotechnical engineering. This test has been used for granular materials with a low sensitivity to water [2, 3], for undrained shear tests on treated geomaterials [4], for soils reinforced with inclusions [5], and for the friction behavior of interfaces [6]. However, it is difficult to investigate the behavior inside the soil box during direct shear and in order to understand the direct shear behavior, it is worthwhile to investigate closed behavior in the soil box.

The aim of this study is to link results of classical direct shear tests with shear behavior in terms of deformation and strain in granular materials. A series of direct shear tests are conducted with a micro-focus X-ray computed tomography (CT) scanner to investigate the behavior of the material placed in the shear box. These tests are conducted with an apparatus specially designed for X-rat CT compatibility. In addition to the images obtained from CT scanning, it is important to discuss quantitative parameters such as displacement and strain. Here, a digital image correlation (DIC) method is used to analyze the deformation and strain in the sample [7]. Moreover, discrete element modeling is used to compare the modeling with behavior obtained in experiments [8]. 
To check the relevance of the calculation of shear behavior with the techniques chosen in this study, sand as a rigid particle and tire chips as elastic particles are tested along with a mixture of the two particles. Sand and tire chips have very different mechanical properties at the particle-scale as well as at the sample-scale, in terms of resilience, compressibility, and elasticity. Therefore, the observation of differences in the shear behavior should be noticeable, in terms of shear resistance as well as of strain distributions. Tire chips have been chosen because there has been increased attention on using such tire products as a material in civil engineering and geotechnical engineering $[9,10]$.

\section{Direct shear test with CT scanning}

Summary of micro-focus X-ray CT

In the past, the authors have performed many studies using an industrial X-ray CT [7, 11, 12]. A micro-focus type X-ray CT, having a resolution higher than that of the industrial one, was also installed at Kumamoto University in 2010. Fig. 1 shows the micro-focus X-ray CT scanned at Kumamoto University, and Fig. 2 shows the scanning chamber which contains the X-ray source, specimen table, and flat panel detector (FPD). In this apparatus, the X-ray is cone-beam type, and so CT scanning can be performed in three dimensions and a large amount of data can be obtained in a relatively short time. The specifications of this scanner are shown in Table 1. 
Direct shear apparatus for X-ray CT scanner

To conduct a direct shear test in the CT room, the following conditions should be met.

1) There should be no obstacles along the direction of X-ray attenuation.

2) The material of the shear box should have good capability of X-ray transmission.

3) To obtain good accuracy of the CT image, there are some restrictions such as the weight of the testing apparatus on the CT table, which should be below $25 \mathrm{~kg}$, and the size of the scanning area under cone-beam type.

Considering these conditions, a new direct shear test apparatus for CT scanning is developed (Fig. 3). Aluminum is used for the shear box due to its X-ray absorption property. Moreover, there are no obstacles around the soil specimen to the X-ray attenuation. Further details can be obtained in the paper by Otani et al. [13].

\section{Materials and test cases}

Fig. 4 shows the materials of the specimens, i.e., No. 3 silica sand and tire chips. The grain size distributions of these materials are shown in Fig. 5. Both the materials have an average grain size close to $2.0 \mathrm{~mm}$ with very narrow and similar size distributions. The particle density was $1.15 \mathrm{~g} / \mathrm{cm}^{3}$ for tire chips and $2.65 \mathrm{~g} / \mathrm{cm}^{3}$ for silica sand. The tire chips were prepared by shredding scrap tires. The particle size was set as $2.0 \mathrm{~mm}$ in average 
after removing all metals and textiles from the scrap tires.

Direct shear tests were conducted on four test cases as shown in Table 2: a sample consisting of only No. 3 silica sand, another sample consisting of only tire chips, and two other samples consisting of a mixture of sand and tire chips (the percentages of tire chips were $20 \%$ and $50 \%$ in volume).

\section{Test procedure}

Fig. 6 presents a schematic of the configuration of the direct shear test apparatus used in this study. The cylindrical soil specimen for direct shear test was $40 \mathrm{~mm}$ in height (half for the lower box and half for the upper one) and $80 \mathrm{~mm}$ in diameter. After preparing specimens, the apparatus was placed in the X-ray CT system and confined with a pressure of $100 \mathrm{kPa}$ until the vertical displacement stabilized. Keeping the upper box fixed, the lower box was moved laterally at a velocity of $0.6 \mathrm{~mm} / \mathrm{min}$ until a relative displacement of $8.0 \mathrm{~mm}$ between the boxes was attained. A series of CT scanning of the soil box were conducted at different displacement steps for each test. Fig. 7 shows the test apparatus placed in the CT room. During the process of CT scanning, the relative shear displacement between the two boxes was stopped. Fig. 8 shows the micro-focus X-ray CT scanning system. The distance from the X-ray tube to the center of the specimen table (FCD) and 
the distance from the X-ray tube to the FPD (FDD), as shown in the figure, should be determined as per the expected accuracy and objectives of scanning. Table 3 shows the conditions of CT scanning in this study.

\section{Discrete element method}

The Discrete element method (DEM) used here is based on molecular dynamics [14]. It is used in three-dimensions with a code called Spherical Discrete Element Code [15]. In many cases, spheres are used as particles in DEM simulations because of their efficiency in terms of computation time. However, it is difficult to reproduce the shear behavior of sand with spherical particles [16]. Several methods exist to improve this aspect, such as introducing a rolling resistance [17] or change the particle shape by using clumps particles [18] or other complex shapes as polyhedral particles [19]. In these simulations, clumps particles were used for the model of sand and tire chips. Clump particles used in these DEM simulations consist of unbreakable assemblies of two identical spheres, as shown in Fig. 9. The parameter to describe the particle shape is called angularity and is defined as follows:

$$
L=\text { angularity } \times 2 R,
$$

where $L$ is the distance between the centers of the two spheres and $R$ is the radius of 
these spheres. An angularity of 0.0 corresponds to a spherical particle and an angularity of 1.0 corresponds to two tangent spheres.

The contact model consists of linear contact laws in both normal and tangential directions (Fig. 10). Normal and tangential forces, $F_{n}$ and $F_{t}$, can be computed from relative normal displacements of two particles in contact, in both directions, and contact stiffnesses, $k_{n}$ and $k_{t}$ :

$$
\begin{aligned}
& F_{n}=k_{n} \varepsilon, \\
& \Delta F_{t}=k_{t} \Delta u_{t}, \text { with }\left|F_{t}\right|<\mu F_{n},
\end{aligned}
$$

where $\varepsilon$ is the particle overlap at the contact point and $\Delta u_{t}$ is the increment of tangential relative displacement at the contact point. A Coulomb friction criterion, coefficient $\mu$, is used to limit the value of the tangential force relative to the normal force. The normal stiffness $k_{n}$ of the contact between two particles $i$ and $j$ of respective diameters $R_{i}$ and $R_{j}$ and of respective stiffness moduli $E_{i}$ and $E_{j}$ is determined as follows:

$$
k_{n}=\frac{R_{i} E_{i}+R_{j} E_{j}}{R_{i}+R_{j}}
$$

The tangential stiffness $k_{t}$ of a contact is determined as a proportion of the normal stiffness $k_{n}: k_{s}=0.75 k_{n}$

The angularity of particles representing tire chips and silica sand was set to 0.7 . The 
relative densities of numerical specimens were considered equal to $90 \%$, corresponding to a void ratio of 0.50 . This was obtained using a radius expansion method with a nonzero friction coefficient during the expansion process.

Figure 11 shows the simulation model of the direct shear test. The width of the shear box used in the numerical modeling was $20 \mathrm{~mm}$ instead of $80 \mathrm{~mm}$ in the experimental case, to limit the number of particles and hence the calculation time. Table 4 presents the mechanical parameters used in the simulations. The numerical parameters for the sand and tire chips particles were determined by simulating a shear test on samples consisting of only sand particles and those consisting of only tire chips particles. The parameters of the numerical models for each material were chosen so that the reproduction of the shear behavior fitted the experimental results obtained for the cases with a single material: sand or tire chips. Two additional cases were studied in the simulation using the parameters determined previously: specimens of sand particles mixed with tire chips particles, with mixing percentages of tire chips of $50 \%$ and $20 \%$ in volume.

4. Results and discussion

Stress - displacement relationship

Fig. 12 shows the experimental data for the relationship between shear stress and shear 
displacement for the direct shear tests. In addition, the results from DEM are plotted in this figure. For the case of silica sand, a peak stress of $140 \mathrm{kPa}$ is obtained at the shear displacement of $2.5 \mathrm{~mm}$, while the case of tire chips shows a monotonic increase in shear stress without any peak. For the mixed specimen with $50 \%$ tire chips, the relationship between shear stress and shear displacement is similar with the specimen with tire chips only. Further, the mixed specimen with $20 \%$ tire chips is an intermediate case between the cases of sand and tire chips. Thus, the shear stress increases as the mixing percentage of tire chip decreases. A similar tendency was also obtained from DEM simulation, as shown in the figure. Based on the comparison between the test results and DEM, the model provides good predictions of the behavior of mixed specimens in terms of shear resistance, as soon as the parameters corresponding to each separate material are determined.

Vertical displacement - shear displacement relationship

Fig. 13 shows the relationship between vertical displacement and shear displacement in the case of experimental and numerical results. For the case of silica sand, the dilatancy is significant, whereas for the case of tire chips, there is a tendency of contractancy. This behavior can be explained by the compressibility of tire chips. For the case of $50 \%$ tire 
chips mixed with sand, the relationship between vertical and shear displacement is close to that for tire chips only. On the other side, there is a tendency of expansion as shear displacement exceeds $2.5 \mathrm{~mm}$ in case of $20 \%$ tire chips mixed with sand. The modification of shear behavior due to the change in mixing percentages can be confirmed. However, in case of only sand, there are some differences in the dilatancy behavior between direct shear tests and DEM results: the dilatancy of sand is overestimated in the DEM model. For the case of mixed sand, the material expansion is overestimated in the numerical modeling. On the other hand, for the case of tire chips, the experimental results are well reproduced by the DEM simulation. Therefore, we can conclude that the behavior of elastic and compressible bodies such as tire chips can be well reproduced in DEM simulations, although the DEM result for sand is overestimated.

\section{CT images}

As shown in Fig. 14, CT scanning was conducted at the displacement levels of A (initial), B $(1.0 \mathrm{~mm}), \mathrm{C}(2.5 \mathrm{~mm}), \mathrm{D}(5.0 \mathrm{~mm})$, and $\mathrm{E}(8.0 \mathrm{~mm})$ during the direct shear test. We observe that there is a stress relaxation during CT scanning in each test. However, when these results are compared with the ones shown in Fig. 12, the results are fairly close and therefore there is no significant effect on stopping shear displacement during CT scanning. 
A CT image is a digital image obtained by spatial distribution of the so-called gray value which has high correlation with material density, and it shows a total of 256 levels of black and white colors. Fig. 15 shows vertical cross-sectional images for all four cases with five displacement levels (A, B, C, D, and E), in which the white color denotes the high-density areas while the black color denotes the low-density areas. The difference in the density of tire chips and sand can be clearly observed in the images. During the test, low-density regions appear around the horizontal boundary between upper and lower shear boxes for the case of sand, while the case of tire chips does not clearly show any low-density areas. These results can also be related to the dilatancy phenomena observed in sand and tire chips, which has rather negative dilatancy as shown in Fig. 13. Moreover, for the cases of the sand and tire chips mixture, a clear low-density area corresponding to dilatancy could not be confirmed as for the case of sand depending on the volume of tire chips in the soil. Fig. 16 shows a detailed analysis on the behavior around the area of strain localization in the soil box for three cases: sand and the two mixed samples. Two different shear displacement levels are also compared with close-up images of the areas shown within the red squares. It is interesting to note that the soil particles rotate and move on the other particles due to shear for the case of sand, although the particles for the mixed sample cases move horizontally without any rotation. Thus, one can conclude 
that the rotation of the sand particles mixed with tire chips are suppressed. This is because the tire chips have elastic property and can easily be compressed. However, these are only visualizations of the behavior and more quantitative analysis should be carried out. This is performed using DIC method.

\section{Strain distributions}

(1) DIC analysis

DIC is a measurement technique which allows the capturing of displacement information of whole flow fields in fractions of a second. In this method, the movement of the particles is calculated under the highest correlation of two images which are before and after the displacement. Of course, it is easy to calculate strains from obtained displacements, and here, the distributions of the displacement vectors, shear strains, and volumetric strains, are calculated using DIC. Fig. 17 shows the details of the DIC analysis. As shown in the figure, the total number of pixels in the image is $950 \times 950$ for one cross section and 950 $\times 740$ for the other cross section of the soil box, in which the size of the correlation window is $15 \times 15 \times 15$ voxels. The size of searching window was chosen properly based the displacement levels. Further details of the DIC method can be obtained from the paper by Takano et al. [7]. 
In this study, DIC analysis was conducted for three cases (the same ones as in Fig. 16) to analyze the effect of tire chips as an elastic material during direct shear of the mixed sample. Fig. 18 shows the DIC result which is the distribution of displacement vectors in the soil box deduced from the CT images of the three cases. Here, one vector is considered as the representative for the size of $15 \times 15 \times 15$ voxels. The amount of displacement is shown in different colors: blue represents relatively small displacement while red represents larger displacement. These vectors are calculated between two successive displacement steps: from $\mathrm{B}$ to $\mathrm{C}$, from $\mathrm{C}$ to $\mathrm{D}$, and from $\mathrm{D}$ to $\mathrm{E}$. These are the relative displacements in the soil, excluding the rigid body displacement of each box. The upper box being fixed, the amount of particle displacement relative to the movement of lower box has been excluded. Therefore, these vectors can focus on the movement of soil particles inside the specimen.

For the case of sand, the movement of soil particles around the horizontal boundary between both shear boxes is significant in any direction as the shear displacement increases. It can also be observed that soil particles in the upper box moved upward while particles in the lower box moved in the same direction as the applied shear displacement. This means that some particles have to run upon the others for the behavior of dilatancy. This explains the global upward displacement of the soil in the upper box. The two cases 
of sand mixed with tire chips have relatively smooth and horizontal displacements. Next, the shear strains and volumetric strains obtained in the experiment are compared with the results of DEM simulations.

\section{(2) Shear strain}

Fig. 19 shows the distribution of shear strain in the specimens for the same three cases as presented in Fig.18. Here, the results of DEM are also presented to compare with the experimental results. The strain values were obtained using the change in the shape of each small area $(15 \times 15 \times 15$ voxels $)$ in the sample due to shearing after DIC analysis. As observed from this figure, high shear strains appear at the edges of the boundary between lower and upper boxes in all the cases at the beginning of step C. Subsequently, these high shear strain areas propagate inside the specimen along this horizontal boundary for the case of sand and also for the case of $20 \%$ mixed sample, although the area is not continuous and narrower for the case of the mixed sample. For the case of $50 \%$ mixed sample, no significant shear banding could be observed. Thus, we can infer that tire chips induce a homogenization of the material so that localization is not clearly observed anymore in these cases. The DEM results are also shown in the same figure, and it is confirmed that the trends of the strain behavior are similar to the DIC results. From these 
results, we can conclude that the propagation and localization of shear strain is reduced by tire chips, and so tire chips could have a potential property to reduce the risk of localized soil failure.

\section{(3) Volumetric strain}

Fig. 20 shows the distribution of volumetric strain in the specimens for the same three cases as for the shear strain. The distribution of volumetric strain shows that volume changes can be confirmed for the case of sand around the horizontal boundary: first, this volume change consists of expansion (B-C), and then there is a mix of expansion and compression areas (C-D and D-E, respectively). In the case of DEM, the soil seems to expand more and no compression areas are observed, resulting in a greater global dilatancy, as shown in Fig. 13. For the mixed sample with $50 \%$ tire chips, there is a tendency of the whole sample to compress. However, for the $20 \%$ case, the tendency of expansion at a displacement of $8.0 \mathrm{~mm}$ is still observed. These observations made at the particle-scale are in agreement with the conclusions on the global vertical displacement drawn from Fig. 13.

\section{Conclusions}


Direct shear behavior was discussed for not only sand but also tire chips and their mixture and due to the discussion on more details of the soil behavior, micro focus X-ray CT was performed during the shear of the specimen. Here, it is the first time ever that the direct shear test was done with a series of X-ray CT scanning at the same time. It is common that the results of X-ray CT is the visualization of the behavior but here in this research, not only its visualization but also the quantitative measures such as displacements and strains in the soils were examined using DIC. A series of DEM simulations for those tests were also conducted to quantify the test results and it is concluded that the results of DEM can explain the test results mostly. Here, in addition to conventional direct shear tests, more details of the local behavior in the soil box can be investigated. Finally, the precise behavior was investigated using X-ray CT and DIC on one side and DEM simulation on the other side. From a qualitative point of view, shearing behavior obtained were very similar between experimental and numerical methods, even if it was observed that in this case, DEM overestimated the dilatancy behavior of the sand. As for the future, the relation between the contact force distribution and the shear distribution is being investigated in details.

References 
[1] Simoni, A., and Houlsby, G.T. (2006). The direct shear strength and dilatancy of sandgravel mixtures, Geotech. Geol. Eng., 24: 523.

[2] Jewell, R. A. (1989). Direct shear tests on sand. Geotechnique, 39 (2), 309-322.

[3] Shibuya, S., Mitachi, T., and Tamate, S. (1997). Interpretation of direct shear box testing of sands as quasi-simple shear. Géotechnique, 47 (4), 769-790.

[4] Okyay, U.S., Dias, D. (2010). Use of lime and cement treated soils as pile supported load transfer platform. Engineering Geology, 114 (1-2), 34-44.

[5] Yetimoglu, T., and Salbas, O. (2003). A study on shear strength of sands reinforced with randomly distributed discrete fibers. Geotextiles and Geomembranes, 21 (2), 103 110.

[6] Wasti, Y., and Ozduzgun, Z.B. (2001). Geomembrane-geotextile interface shear properties as determined by inclined board and direct shear box test. Geotextiles and Geomembranes, 19 (1), 45-57.

[7] Takano, D, Lenoir, N., Otani, J., and Hall, S.A. (2015). Localized deformation in a wide-grained sand under triaxial compression revealed by X-ray tomography and digital image correlation, Soils and Foundations, 55 (4), 906-915.

[8] Chevalier, B., and Otani, J. (2011). Arching observation in three-dimensional trapdoor problem with X-ray CT and discrete element method, Soils and Foundations, 51 (3), 
459-469.

[9] Youwai, S., and Bergado, D. T. (2003). Strength and deformation characteristics of rubber shredded tire - sand mixtures. Can. Geotech. J., 40 (2), 254-264.

[10] Hazarika, H., Yasuhara, K., and Hyodo, M. (2009). Sustainable material recycling of scrap tires-few innovative applications in Japan, International Joint Symposium on Geodisaster Prevention and Geoenvironment in Asia, JS-Fukuoka 2009, 179-184.

[11] Otani, J., Mukunoki, T., and Obara, Y. (2000). Application of X-ray CT method for characterization of failure in soils, Soils and Foundations, 40 (2), 111-118.

[12] Taniguchi, S., Otani, J., and Kumagai, M. (2014). A study on characteristics evaluation to control quality of asphalt mixture using X-ray CT, Road Materials and Pavement Design, 15 (4), 892-910.

[13] Otani, J., Mukunoki, T., and Obara, Y. (2002). Characterization of failure in sand under triaxial compression using an industrial X-ray CT scanner, International Journal of Physical Modelling in Geotechnics, 2 (1), 15-22.

[14] Cundall, P. A., and Strack, O. D. L. (1979). A discrete numerical model for granular assemblies, Géotechnique, 29 (1), 47-65.

[15] Magnier, S. A., and Donze, F. V. (1997). Discrete Element Project, Université du Québec-Montréal. 
[16] Katzenbach, R., and Schmitt (2004). A Micromechanical modeling of granular materials under triaxial and oedometric loading. In Numerical Modeling in Micromechanics via Particle Methods, Shimizu, Hart, Cundall (eds), Taylor and Francis Group (London), pp. 313-322.

[17] Jiang, M., Shen, Z., and Wang, J. (2015). A Novel Three-Dimensional Contact Model for Granulates Incorporating Rolling and Twisting Resistances. Computers and Geotechnics, 65, 147-163.

[18] Gao, G., and Meguid, M. (2018). Effect of particle shape on the response of geogrid-reinforced systems: Insights from 3D discrete element analysis. Geotextiles and Geomembranes. 46, 685-698.

[19] Feng, Y. T., Han, K., and Owen, D.R.J. (2012). Energy-conserving contact interaction models for arbitrarily shaped discrete elements. Computer Methods in Applied Mechanics and Engineering, 205-208, 169-177. 


\section{List of figures by order of citation in the text:}

Figure 1. View of the micro-focus X-ray CT scanner in Kumamoto University.

Figure 2 View of the scanning chamber of the X-ray CT scanner, including the X-ray source, specimen table, and flat panel detector (FPD).

Figure 3. View of the direct shear test apparatus made of aluminum.

Figure 4. View of the granular materials tested: tire chips (left) and No. 3 silica sand (right).

Figure 5. Particle size distribution of the tire chips and No. 3 silica sand.

Figure 6. Schematic of the configuration of the direct shear test apparatus.

Figure 7. View of the scanning chamber with the direct shear apparatus placed on the specimen table.

Figure 8. Diagram of the X-ray CT scanning system.

Figure 9. Clump particle used to model tire chips of No. 3 silica sand particle.

Figure 10. Diagram of the linear contact model with a Coulomb friction criterion.

Figure 11. Representation of a sample material in the simulation model of the direct shear test.

Figure 12. Results of the direct shear tests: shear stress versus shear displacement for the experimental tests and numerical simulations. "Exp." denotes experiment. 
Figure 13. Results of the direct shear tests: vertical displacement versus shear displacement for the experimental tests and numerical simulations. "Exp." denotes experiment.

Figure 14. Shear stress versus shear displacement for the experimental tests showing the effect of stopping the shearing for the purpose of scanning (A, B, C, D, and E).

Figure 15. Vertical cross-sectional CT images obtained at the different scanning points A to E for every sample tested.

Figure 16. Detailed view of the shearing zone on the cross-sectional CT images obtained at the scanning points $\mathrm{D}$ and $\mathrm{E}$.

Figure 17. Details of DIC analysis.

Figure 18. Results of DIC analysis showing the displacement vectors of the material in the sample between two successive scanning points (B-C, C-D, and D-E).

Figure 19. Distribution of shear strain in a vertical cross section of the samples, obtained from experimental results (DIC) or numerical simulations. Results are calculated between two successive scanning points from A to E.

Figure 20. Distribution of volumetric strain in a vertical cross section of the samples, obtained from experimental results (DIC) or numerical simulations. Results are calculated between two successive scanning points from A to E. 


\section{List of tables:}

Table 1. Specifications of the micro-focus X-ray CT scanner in Kumamoto University.

Table 2. Composition of the different specimens tested.

Table 3. Conditions chosen for the CT scanning of the specimens.

Table 4. Parameters of the numerical simulations. 


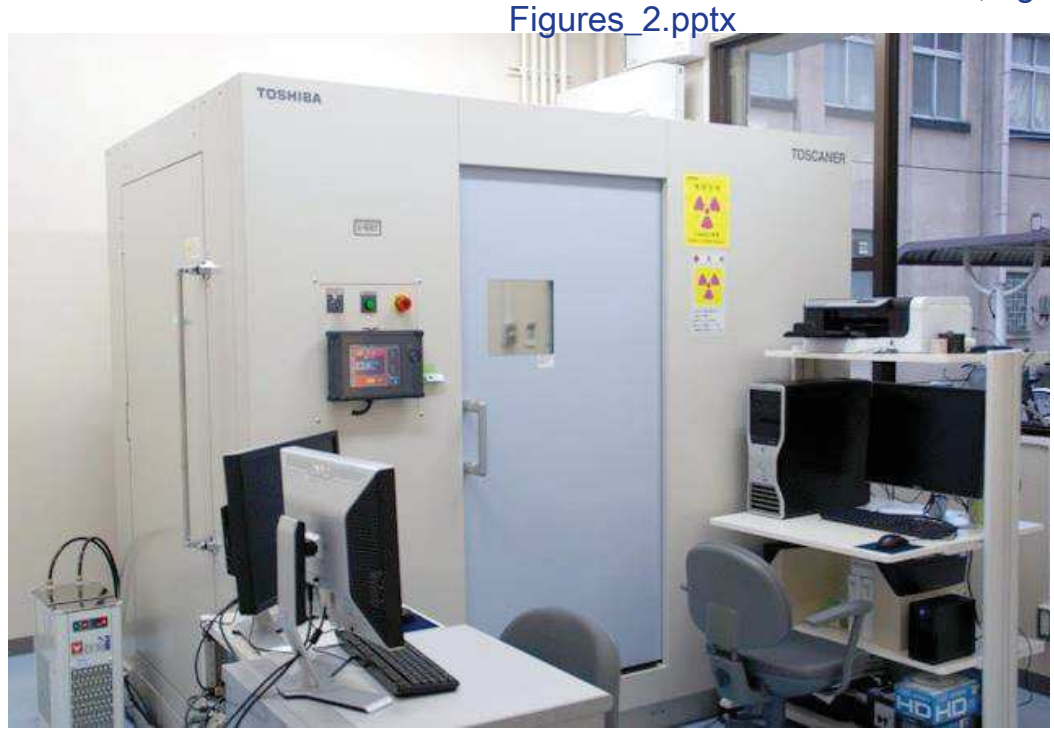

Fig. 1 View of the micro-focus X-ray CT scanner in Kumamoto University.

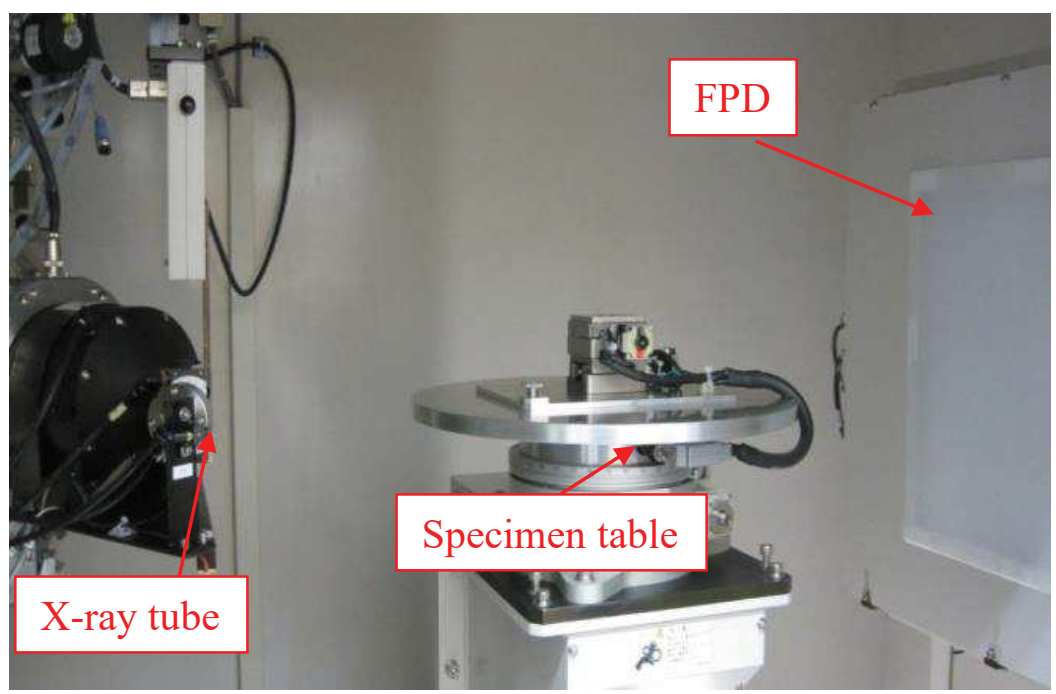

Fig. 2 View of the scanning chamber of the X-ray CT scanner, including the X-ray source, specimen table, and flat panel detector (FPD).

Table 1. Specifications of the micro-focus X-ray CT scanner in Kumamoto University.

\begin{tabular}{lc}
\hline TOSCANER-32300 FPD & \\
\hline Max. voltage & $230 \mathrm{kV}$ \\
Max. current & $600 \mu \mathrm{A}$ \\
Min. focus size & $4 \mu \mathrm{m}$ \\
Max. projection views & 4800 \\
Max. accumulation per 1 view & 50 \\
Max. weight of specimen & $245 \mathrm{~N}$ \\
Max. scanning area & $\varphi: 400 \mathrm{~mm}, \mathrm{~h}: 500 \mathrm{~mm}$ \\
Scanning method & single scan \\
Image matrix & cone scan \\
Resolution performance & $512^{2}, 1024^{2}, 2048^{2}$ \\
Detector & $5 \mu \mathrm{m}$ \\
& $2000 \times 2000$ \\
\hline
\end{tabular}




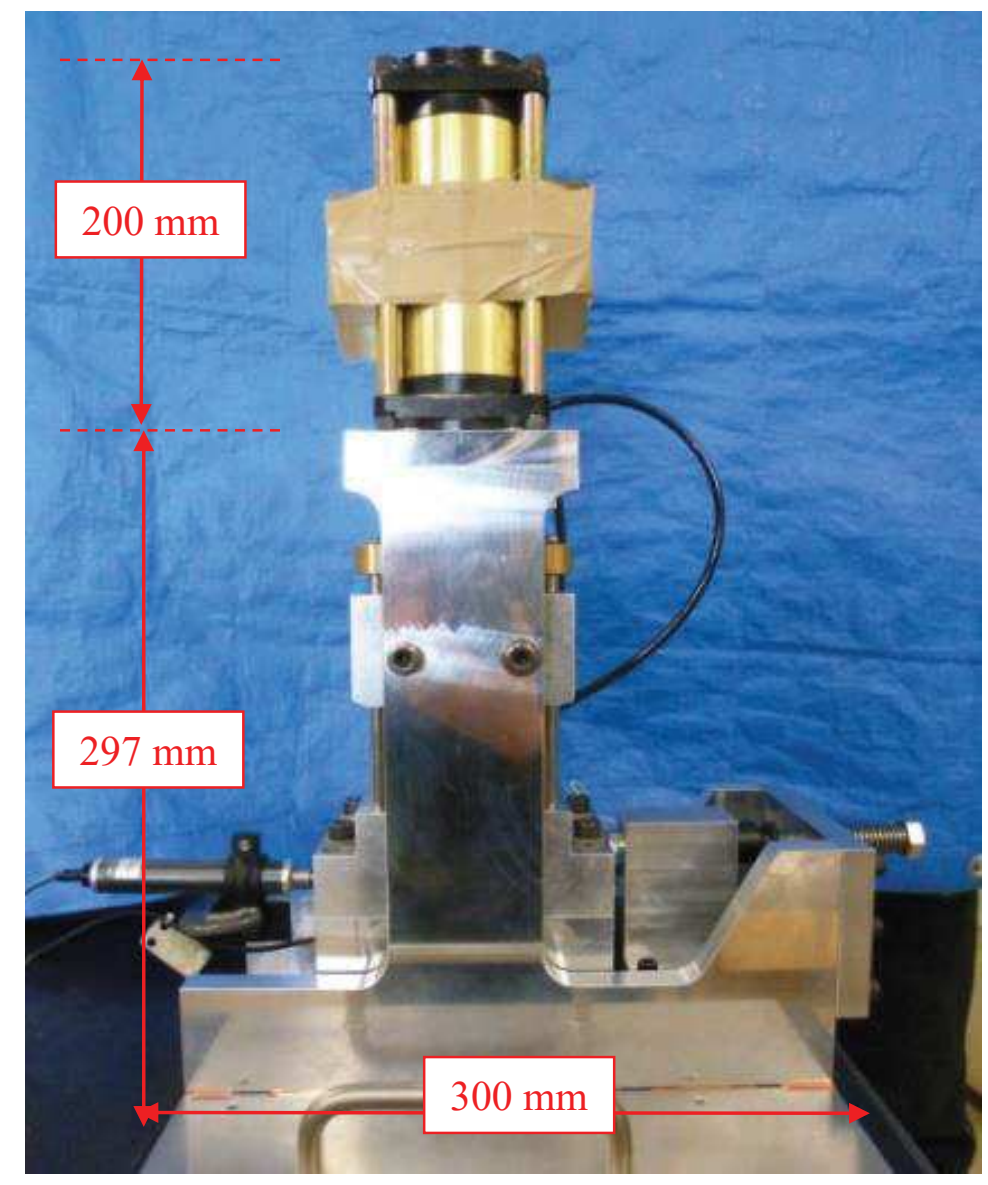

Fig. 3 View of the direct shear test apparatus made of aluminum.

Tire chips No.3 silica sand

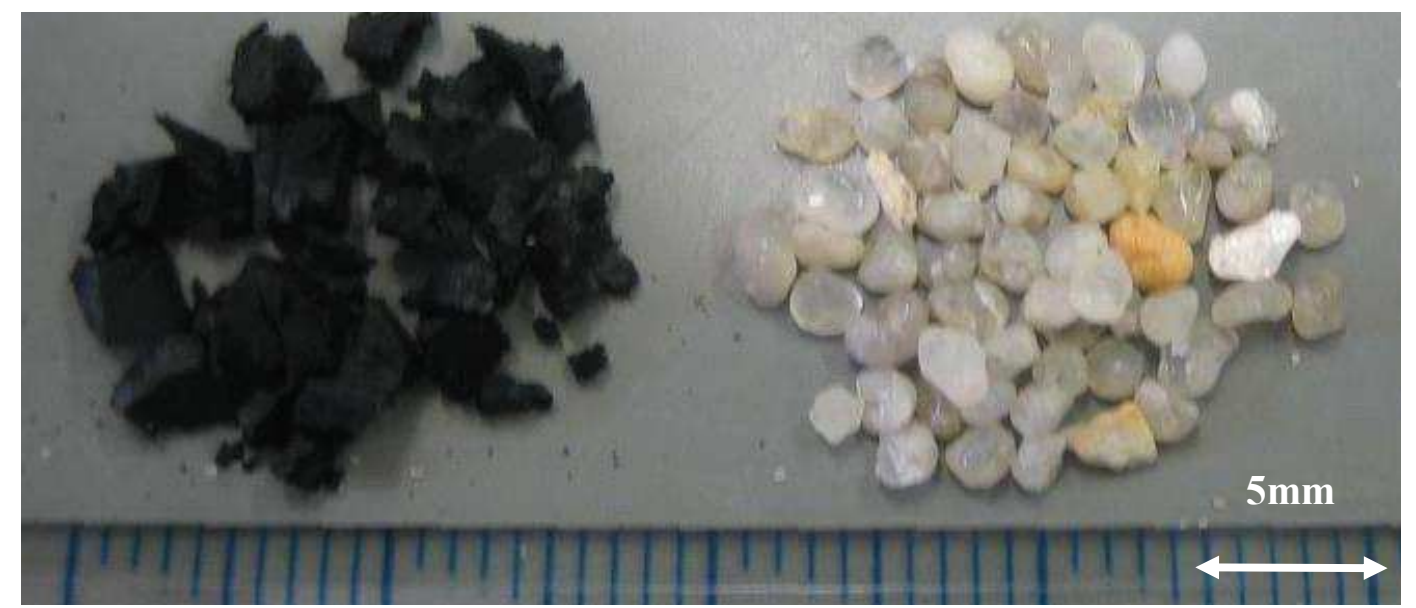

Fig. 4 View of the granular materials tested: tire chips (left) and No. 3 silica sand (right). 


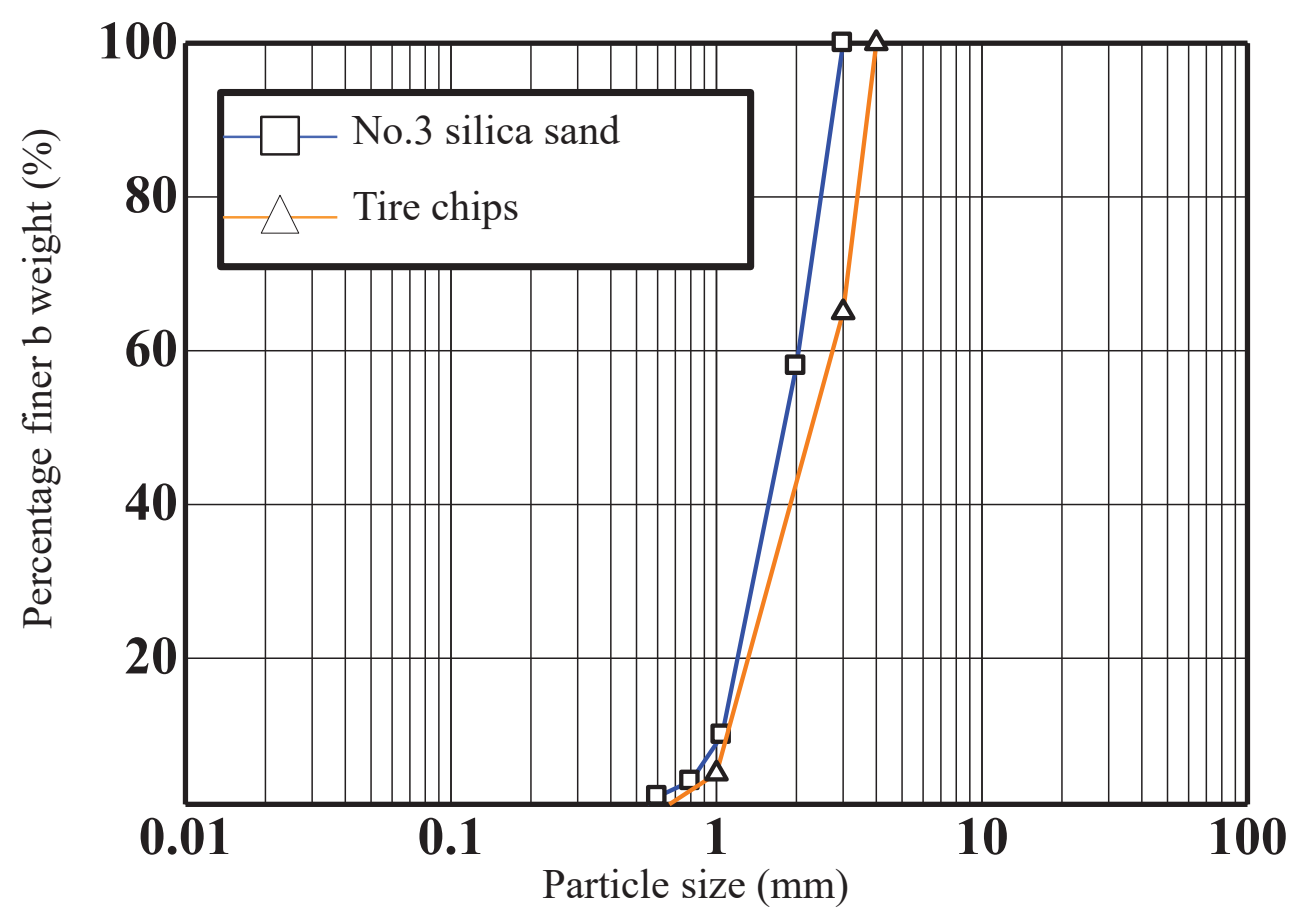

Fig. 5 Particle size distribution of the tire chips and No. 3 silica sand.

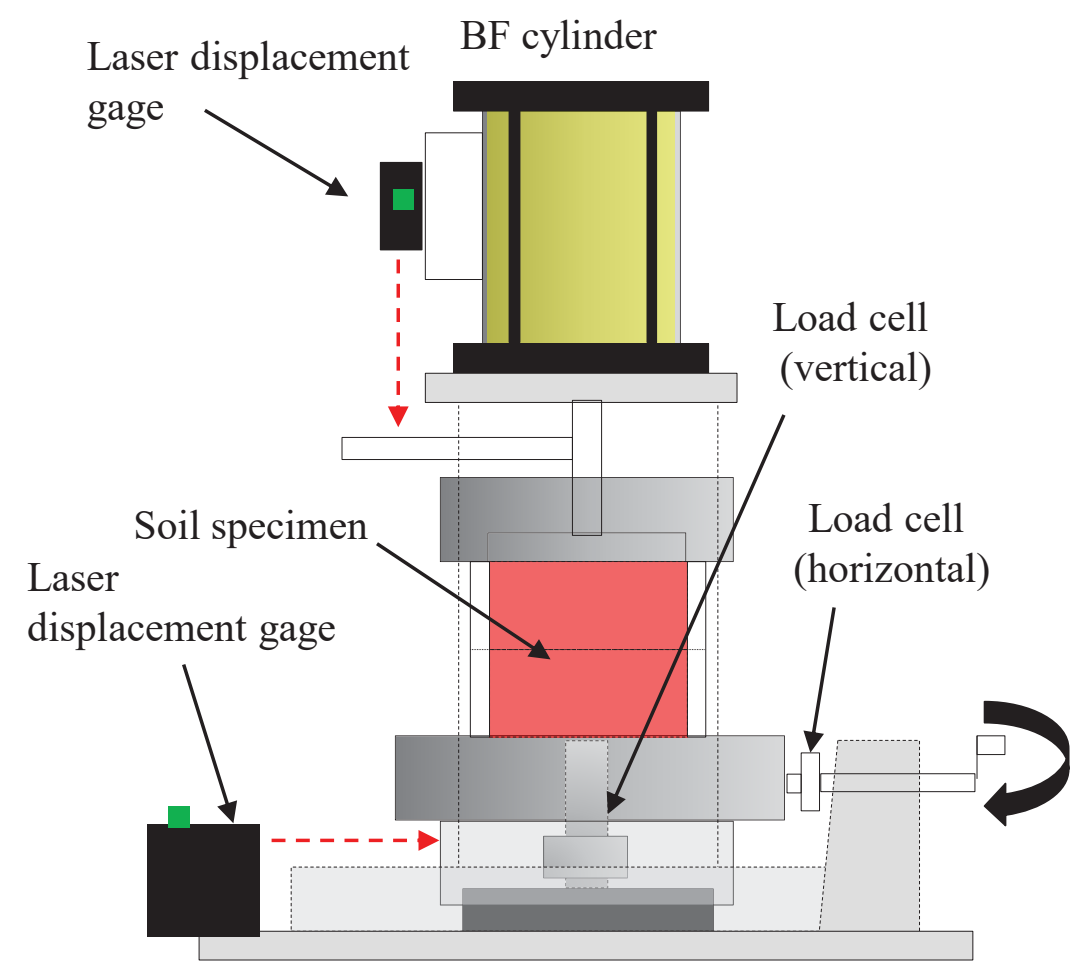

Fig. 6 Schematic of the configuration of the direct shear test apparatus. 
Table 2. Composition of the different specimens tested.

\begin{tabular}{c|ccc}
\hline Test case & $\begin{array}{c}\text { Mixing ratio Void ratio } \\
(\%)\end{array}$ & $\begin{array}{c}\text { Dry density } \\
\left(\mathrm{g} / \mathrm{cm}^{3}\right)\end{array}$ \\
\hline No.3 silica sand & $100: 0$ & 0.59 & 1.66 \\
Tire chips & $0: 100$ & 0.55 & 0.75 \\
$20 \%$ mixed & $80: 20$ & 0.57 & 1.47 \\
$50 \%$ mixed & $50: 50$ & 0.56 & 1.20 \\
\hline
\end{tabular}

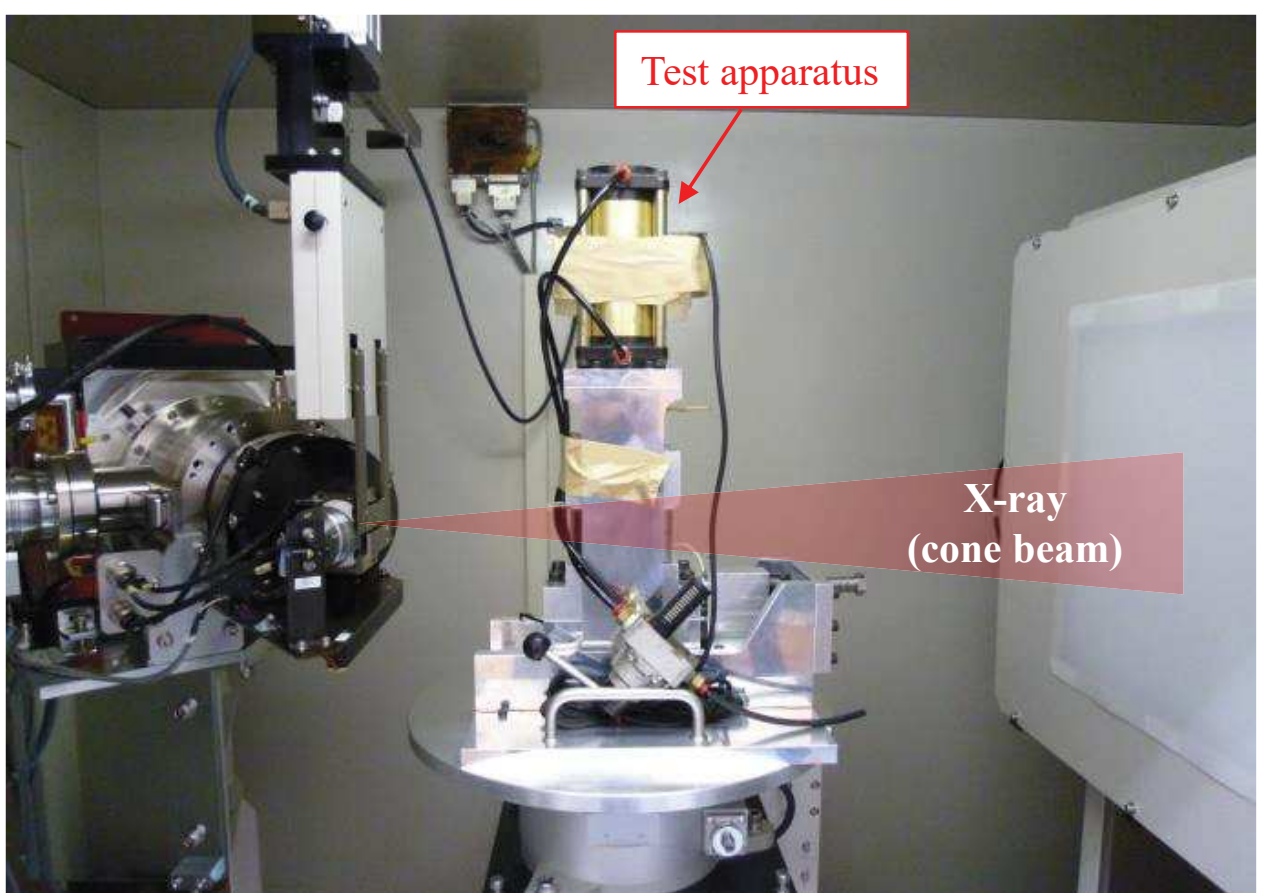

Fig. 7 View of the scanning chamber with the direct shear apparatus placed on the specimen table.
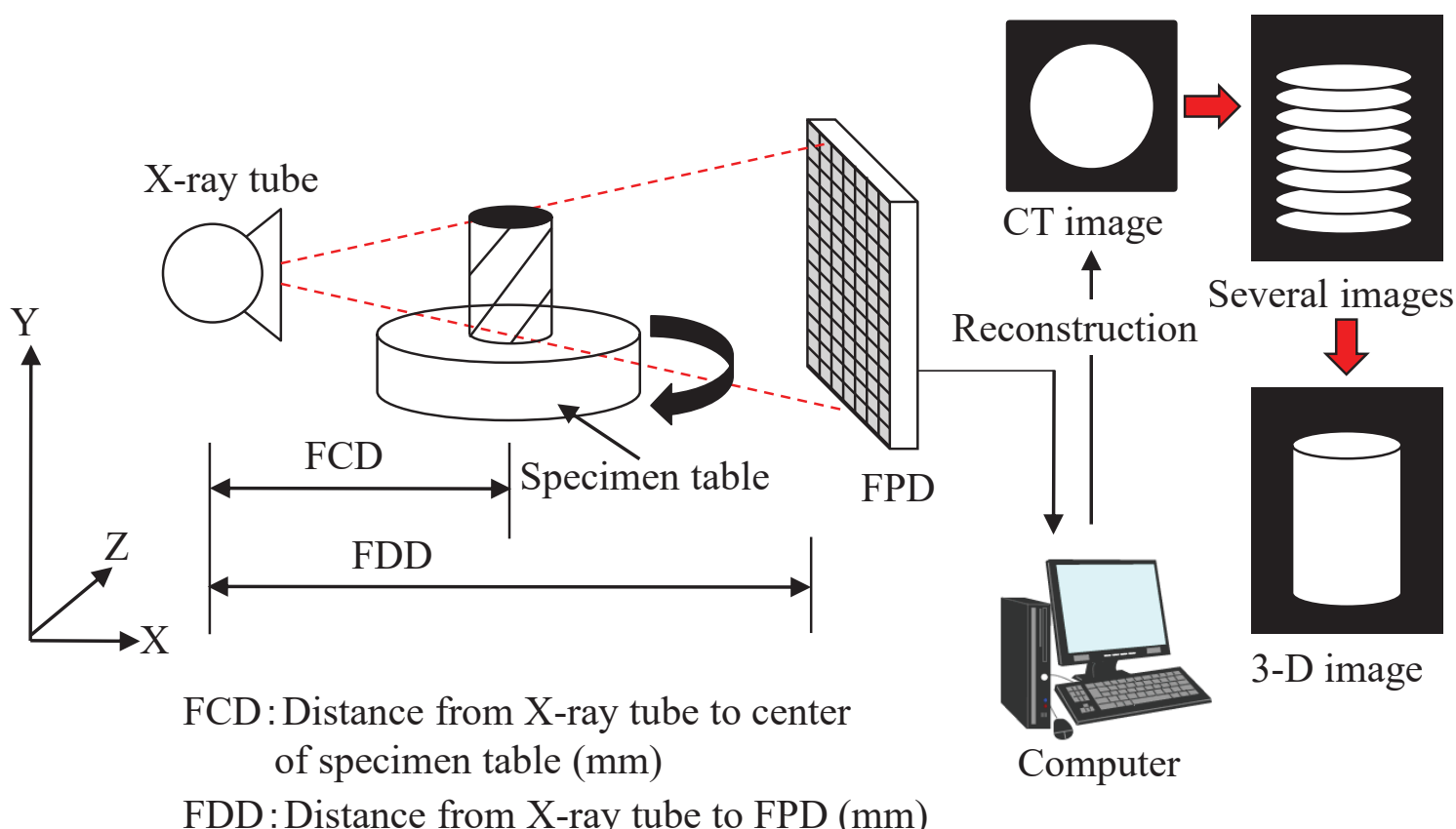

FDD:Distance from X-ray tube to FPD $(\mathrm{mm})$

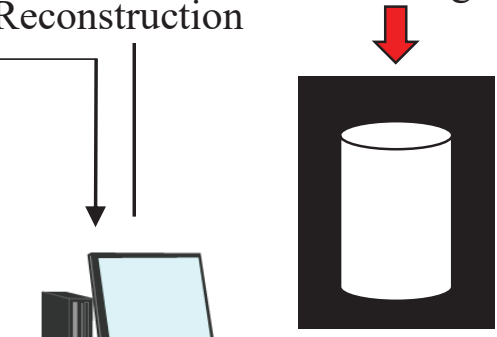

3-D image

Fig. 8 Diagram of the X-ray CT scanning system. 
Table 3. Conditions chosen for the CT scanning of the specimens.

\begin{tabular}{lc}
\hline \multicolumn{1}{c}{ Parameter } & Value \\
\hline Voltage & $210 \mathrm{kV}$ \\
Current & $300 \mu \mathrm{A}$ \\
Image matrix & $1024 \times 1024$ \\
Projection views & 1000 \\
Accumulation per 1 view & 5 \\
Thickness of slice & $90 \mu \mathrm{m}$ \\
Scan pitch & $60 \mu \mathrm{m}$ \\
Scanning method & cone scan \\
Resolution & $106 \mu \mathrm{m}$ \\
Scanning steps & initial, $1 \mathrm{~mm}, 2.5 \mathrm{~mm}$, \\
FCD: Distance from X-ray & $5 \mathrm{~mm}, 8 \mathrm{~mm}$ \\
tube to center of specimen table & $235 \mathrm{~mm}$ \\
FDD: Distance from X-ray & $800 \mathrm{~mm}$ \\
tube to FPD &
\end{tabular}

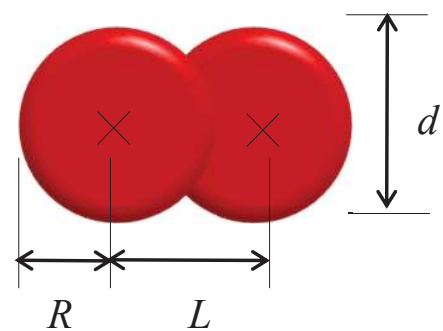

Fig. 9 Clump particle used to model tire chips of No. 3 silica sand particle.

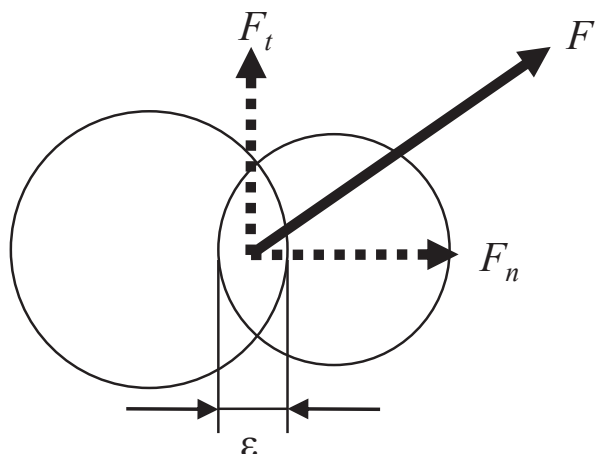

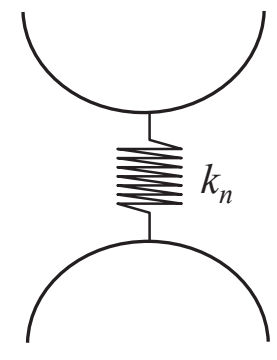

Normal direction

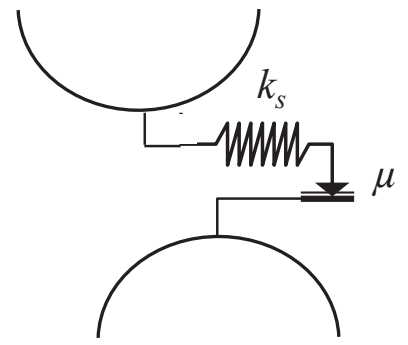

Tangential direction

Fig. 10 Diagram of the linear contact model with a Coulomb friction criterion. 


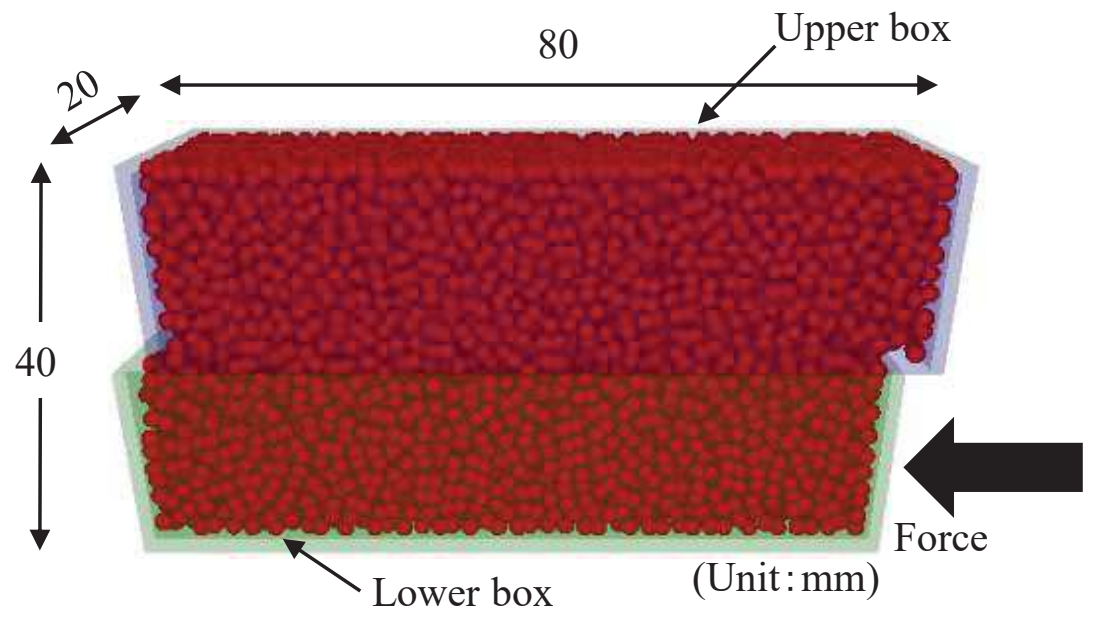

Fig. 11 Representation of a sample material in the simulation model of the direct shear test.

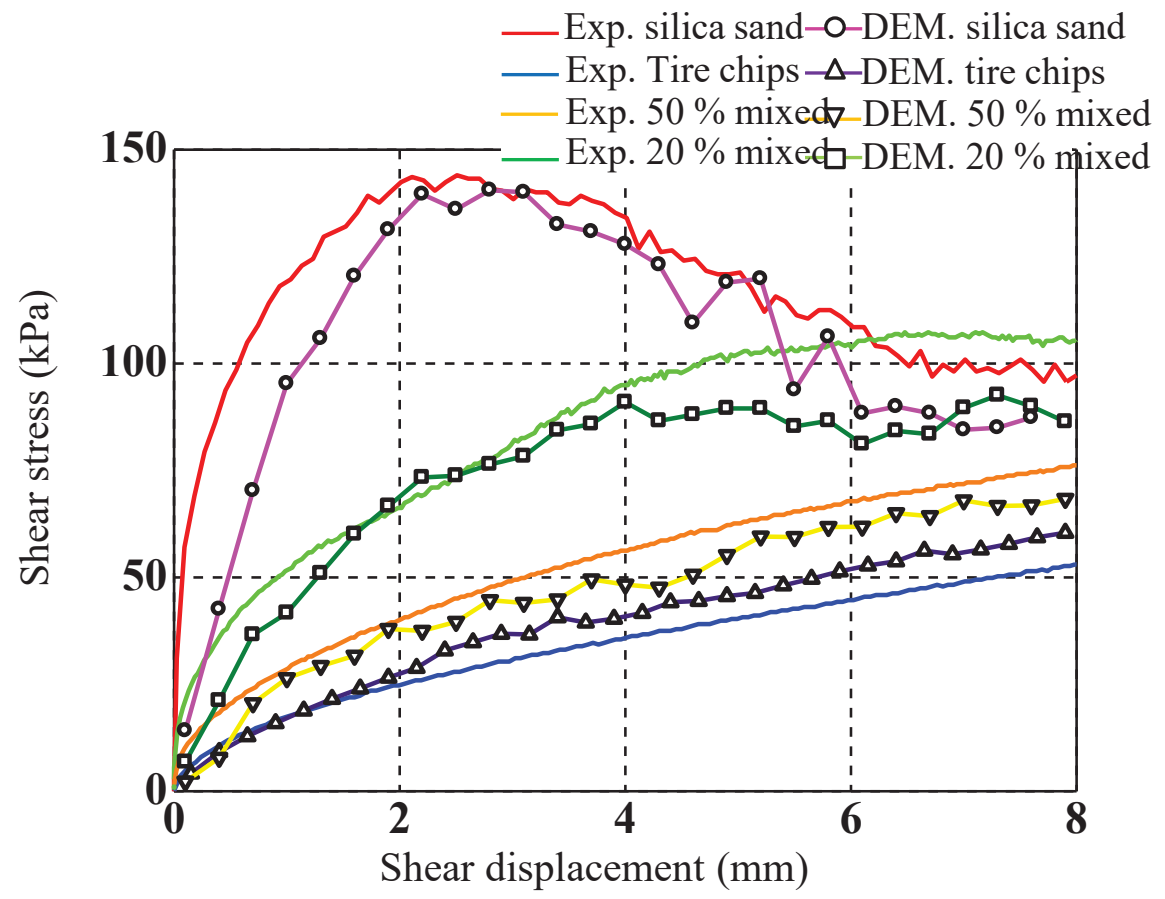

Fig. 12 Results of the direct shear tests: shear stress versus shear displacement for the experimental tests and numerical simulations. "Exp." denotes experiment.

Table 4. Parameters of the numerical simulations.

\begin{tabular}{lcc}
\hline & No.3 silica sand & tire chips \\
\hline Particle density $\left(\mathrm{g} / \mathrm{cm}^{3}\right)$ & 2.65 & 1.15 \\
Particle shape (angularity) & 0.7 & 0.7 \\
Diameter $(\mathrm{mm})$ & 1.95 & 2.04 \\
Confining pressure $(\mathrm{kPa})$ & 100 & 100 \\
Friction angle $(\mathrm{deg})$ & 35 & 10 \\
Normal stiffness $\left(\mathrm{N} / \mathrm{mm}^{3}\right)$ & $2.24 \times 10^{9}$ & $1.12 \times 10^{7}$ \\
$\begin{array}{l}\text { Tangential to normal stiffness } \\
\text { ratio }\end{array}$ & 0.75 & 0.75 \\
\hline
\end{tabular}


_Exp. silica sand -o-DEM. silica sand

-Exp. tire chips $-\triangle$ DEM. tire chips

Exp. $50 \%$ mixed $\nabla$ DEM. $50 \%$ mixed

Exp. $20 \%$ mixed $\square$ DEM. $20 \%$ mixed

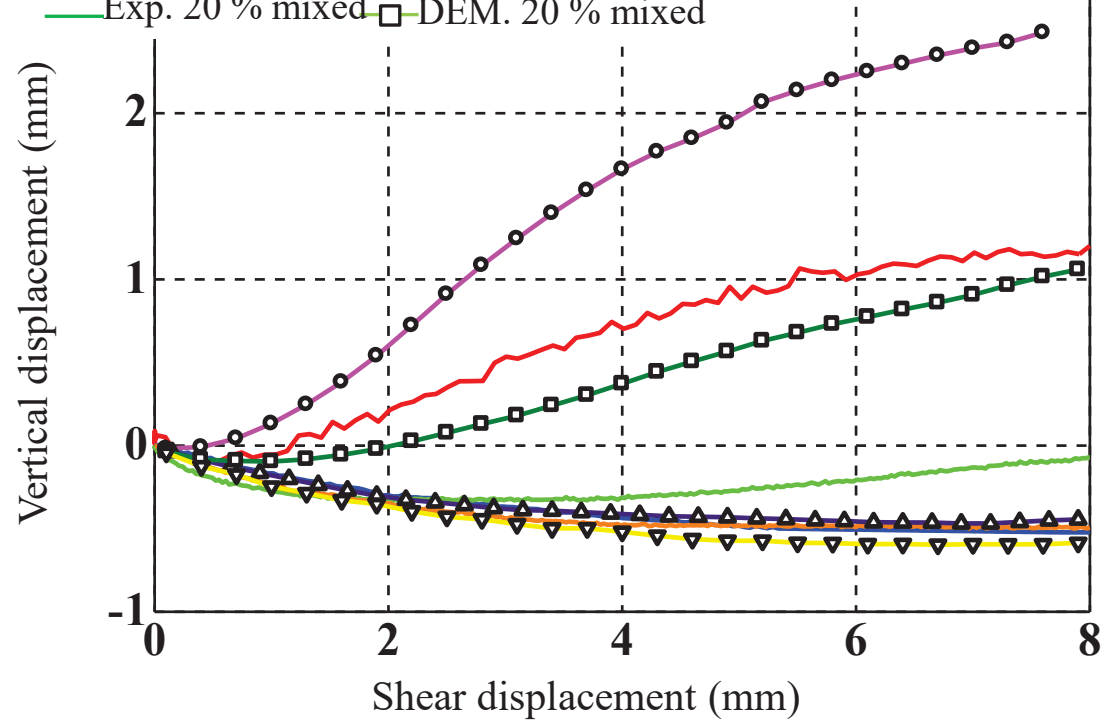

Fig. 13 Results of the direct shear tests: vertical displacement versus shear displacement for the experimental tests and numerical simulations. "Exp." denotes experiment.

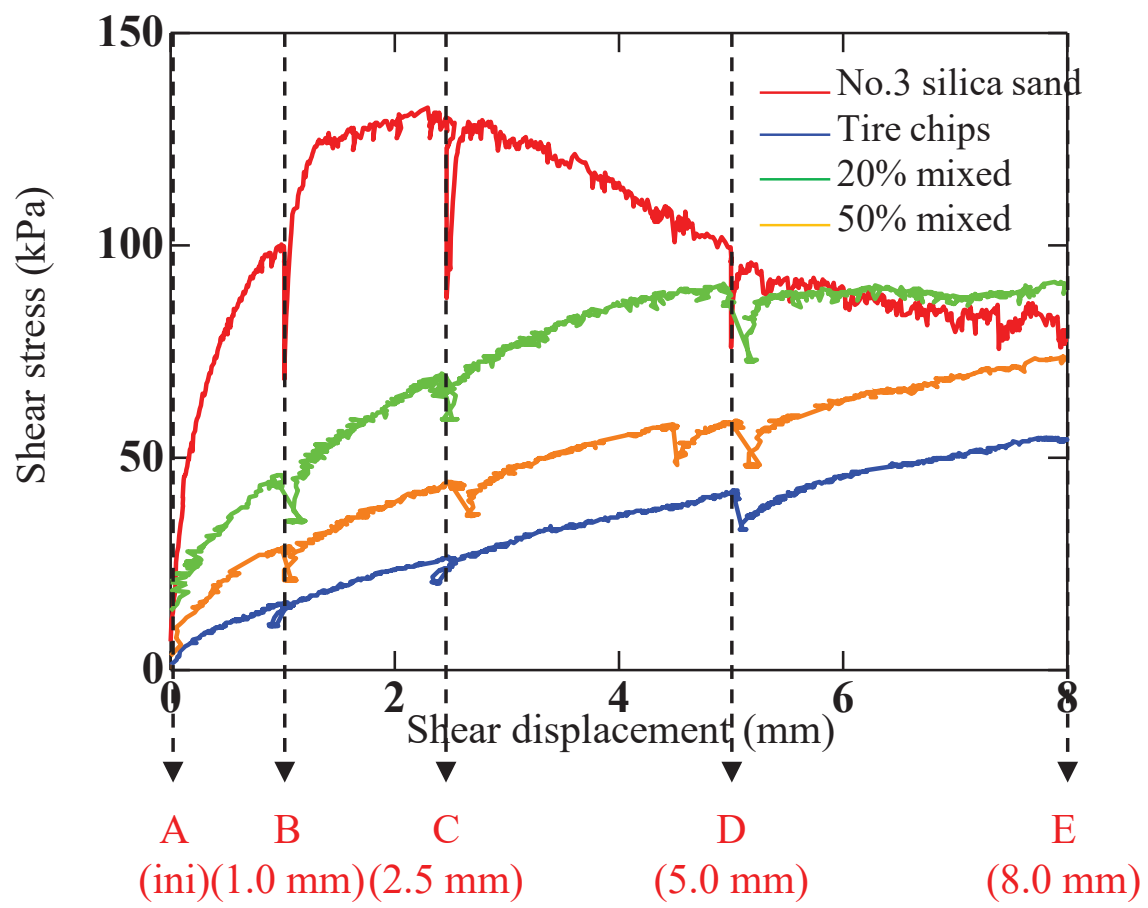

Fig. 14 Shear stress versus shear displacement for the experimental tests showing the effect of stopping the shearing for the purpose of scanning (A, B, C, D, and E). 


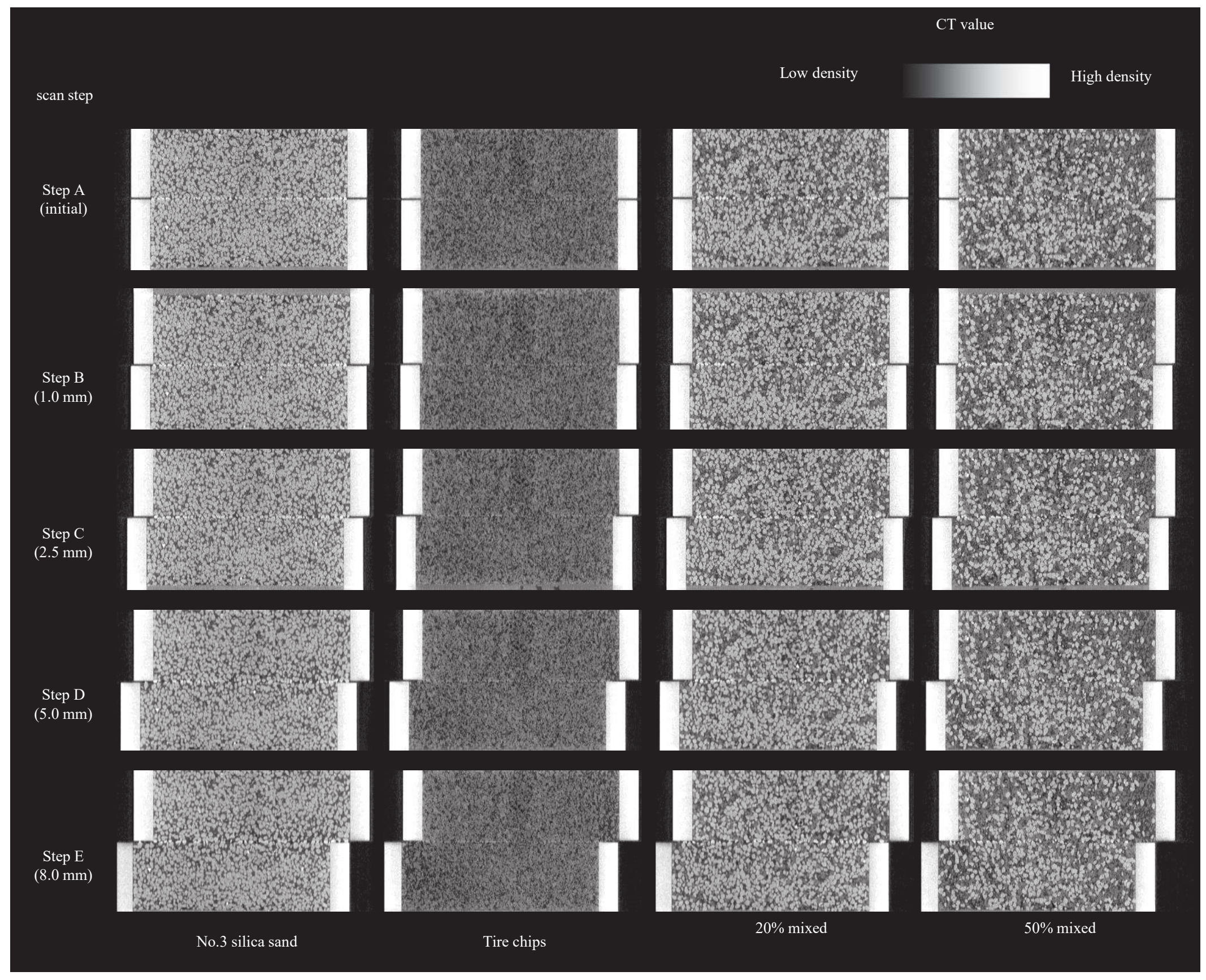

Fig. 15 Vertical cross-sectional CT images obtained at the different scanning points A to E for every sample tested. 

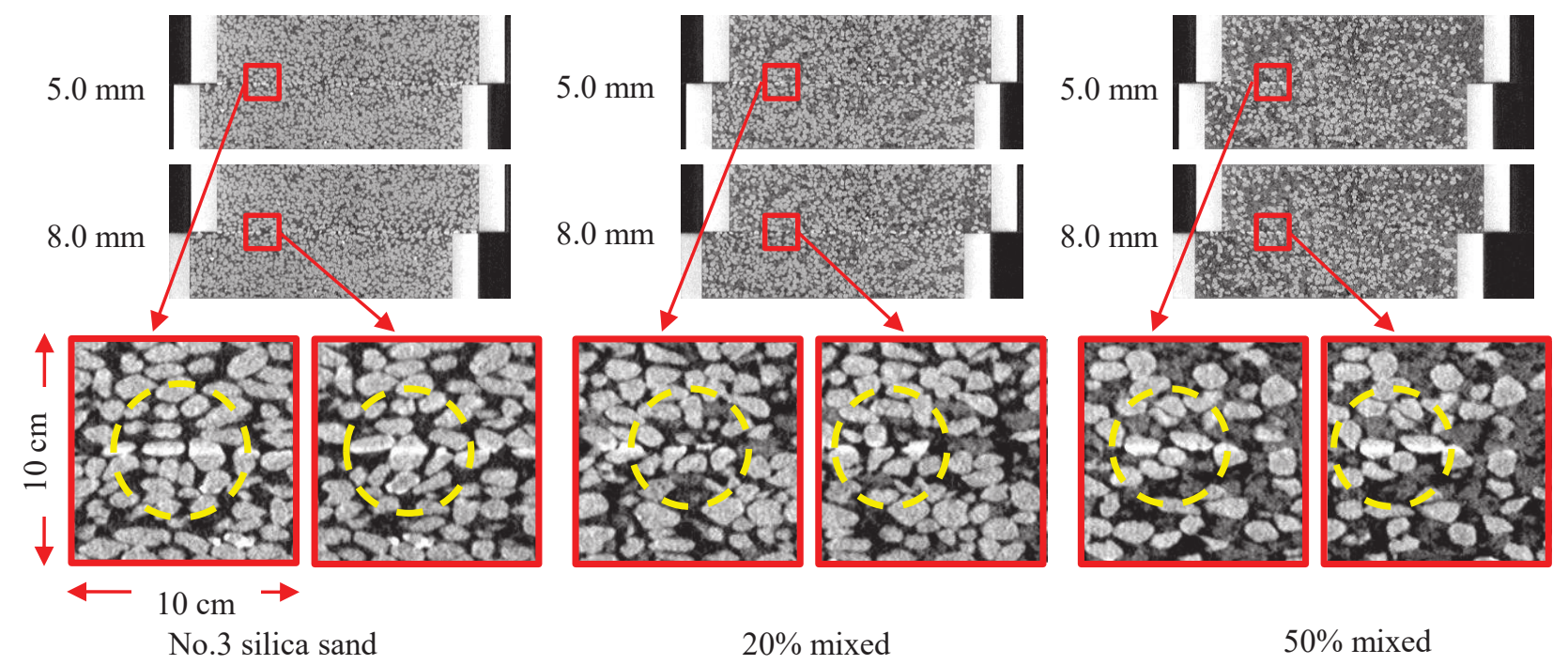

Fig. 16 Detailed view of the shearing zone on the cross-sectional CT images obtained at the scanning points $\mathrm{D}$ and $\mathrm{E}$.

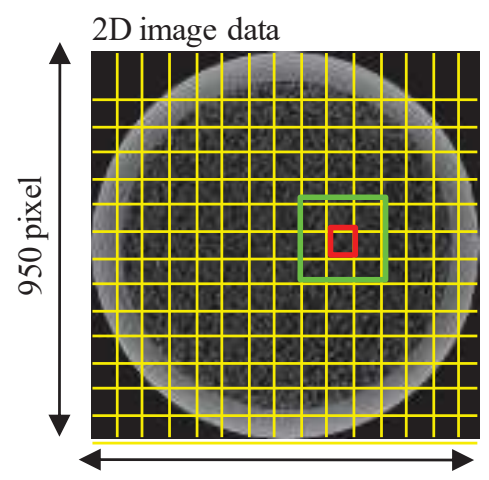

950 pixel

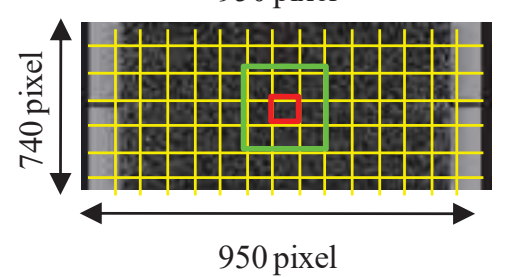

Fig. 17 Details of DIC analysis.

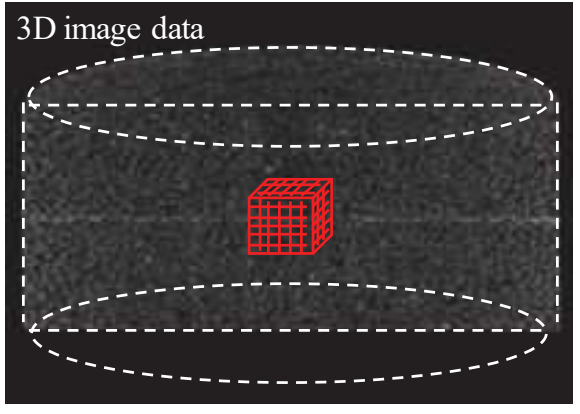

reference

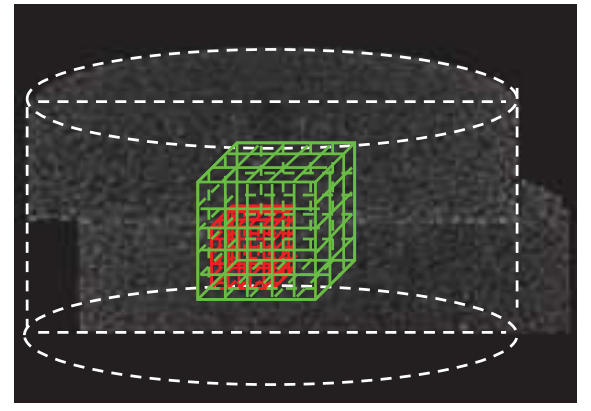

deformed
: correlation window
$\left(15^{3}\right.$ voxel $)$

: search window

(depending on shear displacement) 


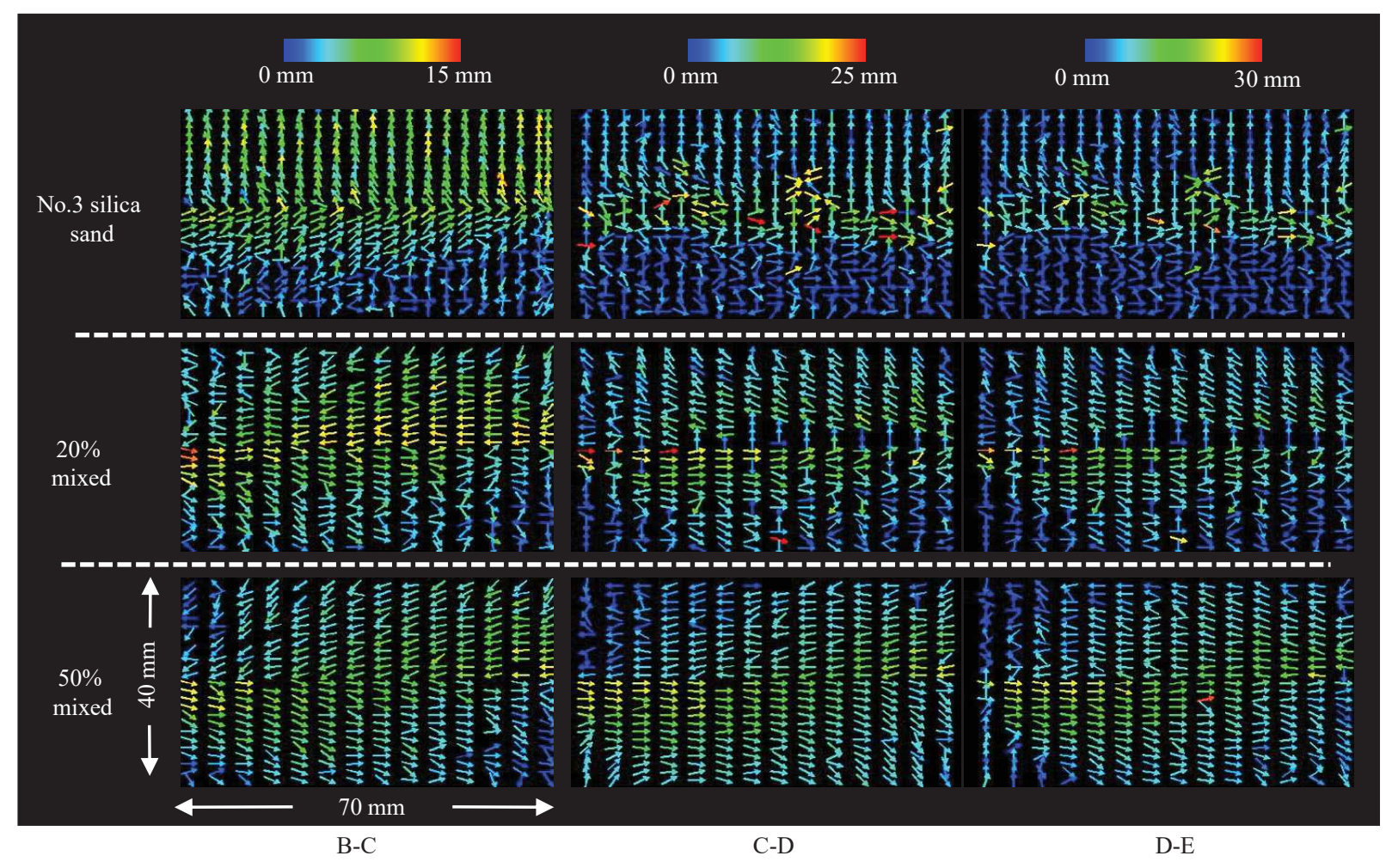

Fig. 18 Results of DIC analysis showing the displacement vectors of the material in the sample between two successive scanning points (B-C, C-D, and D-E). 


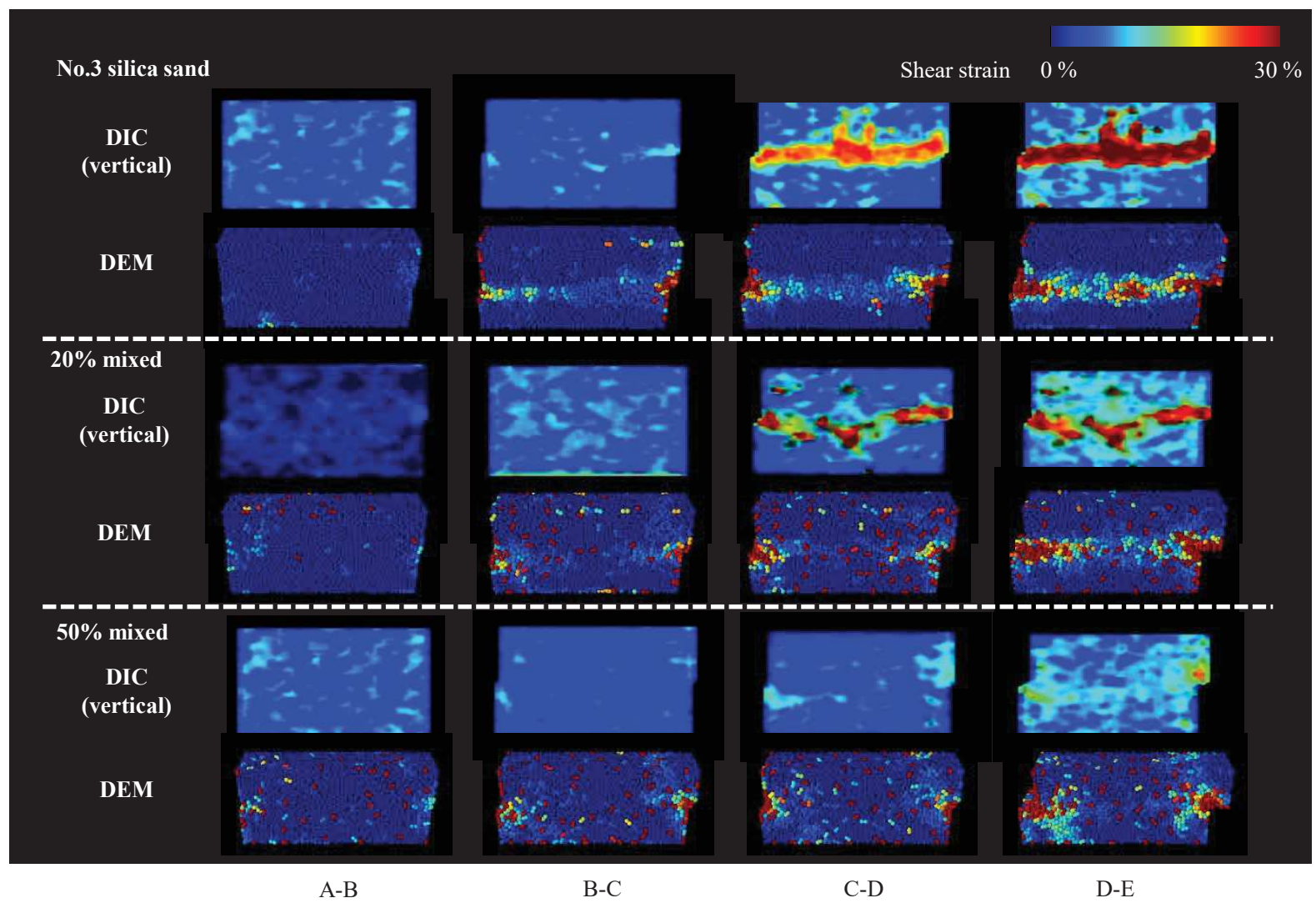

Fig. 19 Distribution of shear strain in a vertical cross section of the samples, obtained from experimental results (DIC) or numerical simulations. Results are calculated between two successive scanning points from A to E.

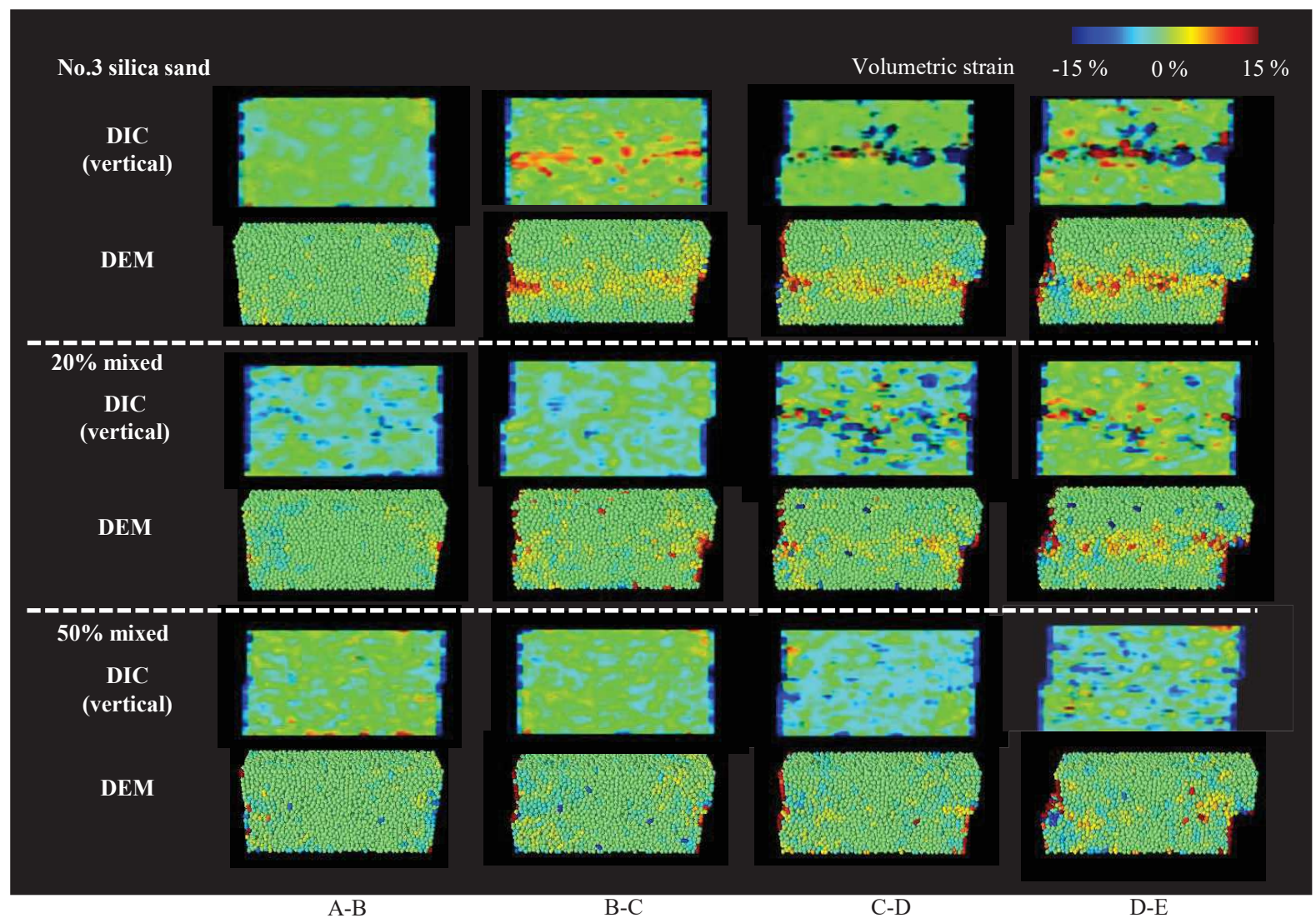

Fig. 20 Distribution of volumetric strain in a vertical cross section of the samples, obtained from experimental results (DIC) or numerical simulations. Results are calculated between two successive scanning points from $\mathrm{A}$ to $\mathrm{E}$. 